\title{
Hippocampal Damage Associated with Prolonged and Fatal Stress in Primates
}

\author{
Hideo Uno, ${ }^{1}$ Ross Tarara,, ${ }^{2,3}$ James G. Else,, ${ }^{2,4}$ Mbaruk A. Suleman,, ${ }^{2}$ and Robert M. Sapolsky ${ }^{2,5}$ \\ ${ }^{1}$ Regional Primate Research Center, The University of Wisconsin, Madison, Wisconsin 53715-1299, 2Institute of Primate \\ Research, National Museums of Kenya, Nairobi, Kenya, ${ }^{3}$ California Primate Center, Davis, California $95616,{ }^{4}$ Yerkes \\ Regional Primate Research Center, Emory University, Atlanta, Georgia 30322, and ${ }^{5}$ Department of Biological Sciences, \\ Stanford University, Stanford, California 94305
}

Sustained exposure to glucocorticoids (GCs), adrenal hormones secreted during stress, can cause neural degeneration in the rat. This is particularly so in the hippocampus, a principal neural target site for GCs, in which GCs can exacerbate the rate of neuron death during normal aging, as well as the severity of neuronal damage after various neurological insults. Thus, stress can be a potent modulator of hippocampal degeneration in the rat. The present report suggests a similar association in the primate. Eight vervet monkeys, housed in a primate center in Kenya, that had died spontaneously from 1984 to 1986 , were found at necropsy to have multiple gastric ulcers; a retrospective, neuropathological study was then done of this opportunistic population. Compared with controls euthanized for other research purposes, ulcerated monkeys had marked hippocampal degeneration that was apparent both quantitatively and qualitatively, and both ultrastructurally and on the light-microscopic level. Minimal damage occurred outside the hippocampus. Damage was unlikely to have been due to an agonal or post-mortem artifact. Instead, ulcerated monkeys appear to have been subject to sustained social stress, perhaps in the form of social subordinance in captive breeding groups: most came from social groups, had significantly high incidences of bite wounds at necropsy, and had hyperplastic adrenal cortices, indicative of sustained GC release. Moreover, the specific hippocampal cell fields damaged in ulcerated animals matched those damaged by GCs in the rodent hippocampus. Thus, this represents the first evidence suggesting that sustained stress, via GC hypersecretion, might be neurodegenerative in the primate.

Glucocorticoids (GCs) are adrenal steroids secreted during stress, whose numerous actions are central to the stress response (Munck et al., 1984). As many of these actions are catabolic, prolonged stress and/or GC exposure can be pathogenic (Krieger, 1982). In the rat, recent work has shown these adverse effects to include neural degeneration. This is particularly so in the hippocampus,

\footnotetext{
Received July 11, 1988; revised Sept. 21, 1988; accepted Sept. 26, 1988.

Support provided by NIH Grant RR-00167 (H.U.), the NIH-sponsored Regional Primate Centers Program and NIH Grant RR-000165 (R.T., J.G.E., M.A.S.), the Harry Frank Guggenheim Foundation, NIH Grant AG-06699 and the Alzheimer's Disease and Related Disorders Association (R.M.S.). Thanks to Carol Thieme, Lon Lohmiller, and Pam Brigham for technical assistance, and for neuropathological suggestions from Drs. A. Hirano and G. Zurhein.

Correspondence should be addressed to Robert Sapolsky at the above address. Copyright (C) 1989 Society for Neuroscience $0270-6474 / 89 / 051705-07 \$ 02.00 / 0$
}

a principal neural target tissue for GCs, with high concentrations of both types of corticosteroid receptors (McEwen et al., 1986). Pharmacologic concentrations damage the structure (Aus der Muhlen and Ockenfels, 1969). Moreover, normal loss of hippocampal neurons with aging is paced by GC exposure, as midage adrenalectomy retards the process, while prolonged exposure to high (though physiological) concentrations of GCs accelerates the neuron loss (Landfield et al., 1981; Sapolsky et al., 1985). GCs disrupt hippocampal glucose utilization (Kadekaro et al., 1988); it has been suggested that this leaves neurons vulnerable to metabolic insults (Sapolsky et al., 1986). Thus, nontoxic concentrations of GCs exacerbate hippocampal damage induced by insults as varied as hypoxia-ischemia, antimetabolites, epileptogenic excitotoxins, and superoxide radical generators (Sapolsky, 1985a, b, 1986a, b; Sapolsky and Pulsinelli, 1985; Theoret et al., 1985; Koide et al., 1986; Sapolsky et al., 1988); furthermore, the exacerbation can be prevented by supplementing the neurons with alternatives to glucose (Sapolsky, 1986b).

These observations suggest that in the rat, stress, via GC secretion, might be an important pacemaker of neuron loss during aging as well as influence the neuropathologic outcome after insults such as hypoxia-ischemia or seizure (Sapolsky et al., 1986). Naturally, it is important to determine whether GCs might also be neurotoxic in the primate brain. Were such the case, prolonged stress should be associated with neural degeneration in the primate, with preferential vulnerability of the hippocampus. In the present study, we have examined a population of monkeys in which these conditions occurred opportunistically, and we find evidence for the predicted pattern of neuropathology.

\section{Materials and Methods}

Subjects. Subjects were adult vervet monkeys (C. aethiops). With the exception of 1 colony-born individual (17F), all had been wild-trapped in Kenya after becoming agricultural pests. Upon transport to the Institute of Primate Research in Nairobi, they were quarantined for 1 month (in isolation, if trapped singly, or in group cages, if trapped with other animals) and then assigned to either social breeding groups or housed in isolation for research purposes. Isolates were housed in 0.6 $\times 0.6 \times 0.68 \mathrm{~m}$ outdoor cages; social groups consisted of 1 male and $3-5$ females in a $6 \times 3 \times 2.5 \mathrm{~m}$ outdoor cage.

Eight monkeys died spontaneously ("ulcerated group"). All had been cachectic, with various illnesses (Table 1). At necropsy, all had multiple gastric ulcers resembling early acute gastric ulcers in humans (Suleman et al., 1984). Ulcerated monkeys had no sign of hemorrhagic fever viruses or gastrointestinal parasites known to cause hemorrhagic lesions in the primate stomach (Suleman et al., 1984). A control group consisted 

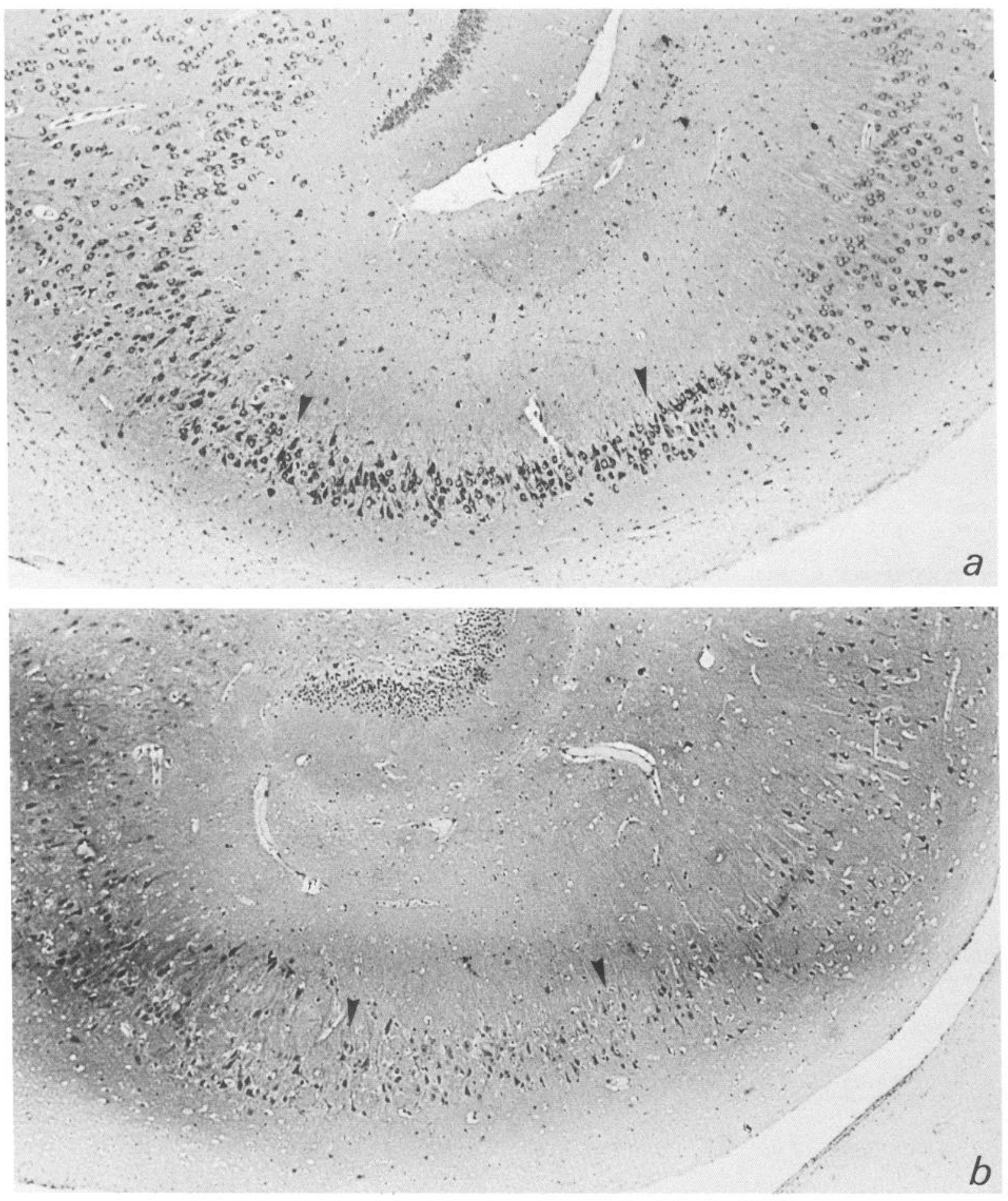

Figure 1. $a$ and $b$ Representative photomicrographs of Ammon's horn neurons (CA1-4) of control animal (a) compared with ulcerated animal (b). Latter shows shrunken and sparse pyramidal neurons and reduced extent of CA3 region (between arrowheads). $\times 85 . c$ and $d$, CA3 neurons from a control animal $(c)$ compared with ulcerated monkey $(d)$. Latter shows dispersed Nissl bodies and irregularly shaped perikarya with atrophic dendritic branches in the stratum lucidum. $\times 500 . e$ and $f$. Ultrastructure of CA3 pyramidal neurons and mossy fiber terminals (arrows, insert) from control $(e)$ and ulcerated $(f)$ monkeys. Latter shows marked atrophy and regressive changes in neuroplasma, nucleus, and dendrites of CA3 neurons and depletion of mossy fiber endings in the stratum lucidum. $\times 3380(\times 11,200$, insert $)$.

of 5 monkeys that were euthanized for other research purposes, plus one animal that died shortly after experimental surgery.

Neuropathological analysis. All analyses were done without knowledge of the groups from which subjects came. For light microscopy, whole hemispheres of brains were fixed in $10 \%$ neutral buffered formalin and hippocampal sections, cut coronally $1 \mathrm{~mm}$ caudal from the uncus, were cut and embedded in glycol methacrylate resin (JB4 embedding kit, Polysciences, Inc.). Other brain regions (striatal ganglia, frontal, preand postcentral and temporal cortex) were cut and prepared similarly. The plastic sections ( $3 \mu \mathrm{m}$ thick) were stained with cresyl violet. For cell counting, only cells with nuclei were included.

For ultrastructural studies, $1 \times 1 \times 2 \mathrm{~mm}$ slices (containing stratum 

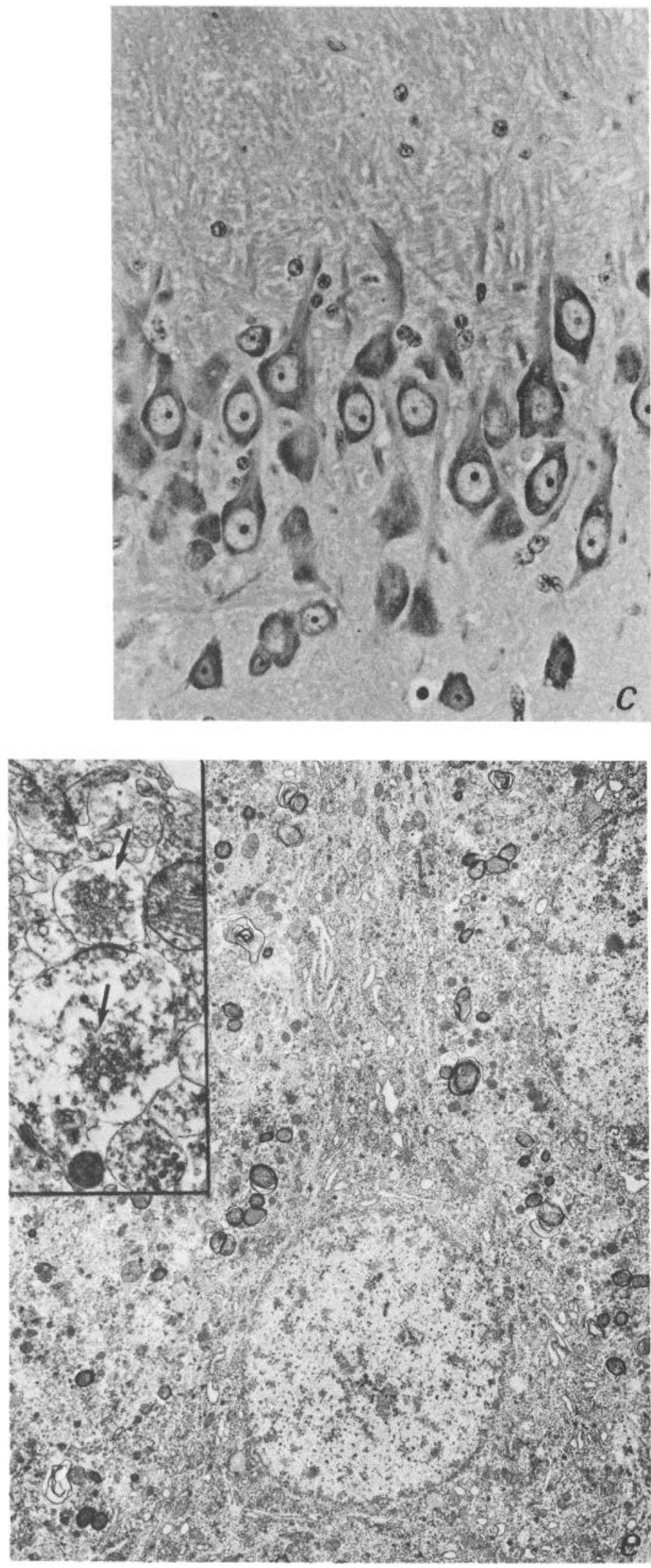

Figure 1. Continued.

pyramidale and lucidum of CA3 region and cortical gray matter of the postcentral gyrus) were cut and refixed with glutaraldehyde-paraformaldehyde solution ( 2.5 and $1 \%$, respectively) for $24 \mathrm{hr}$. Tissues were processed routinely and observed by a Hitachi 200 electron microscope.
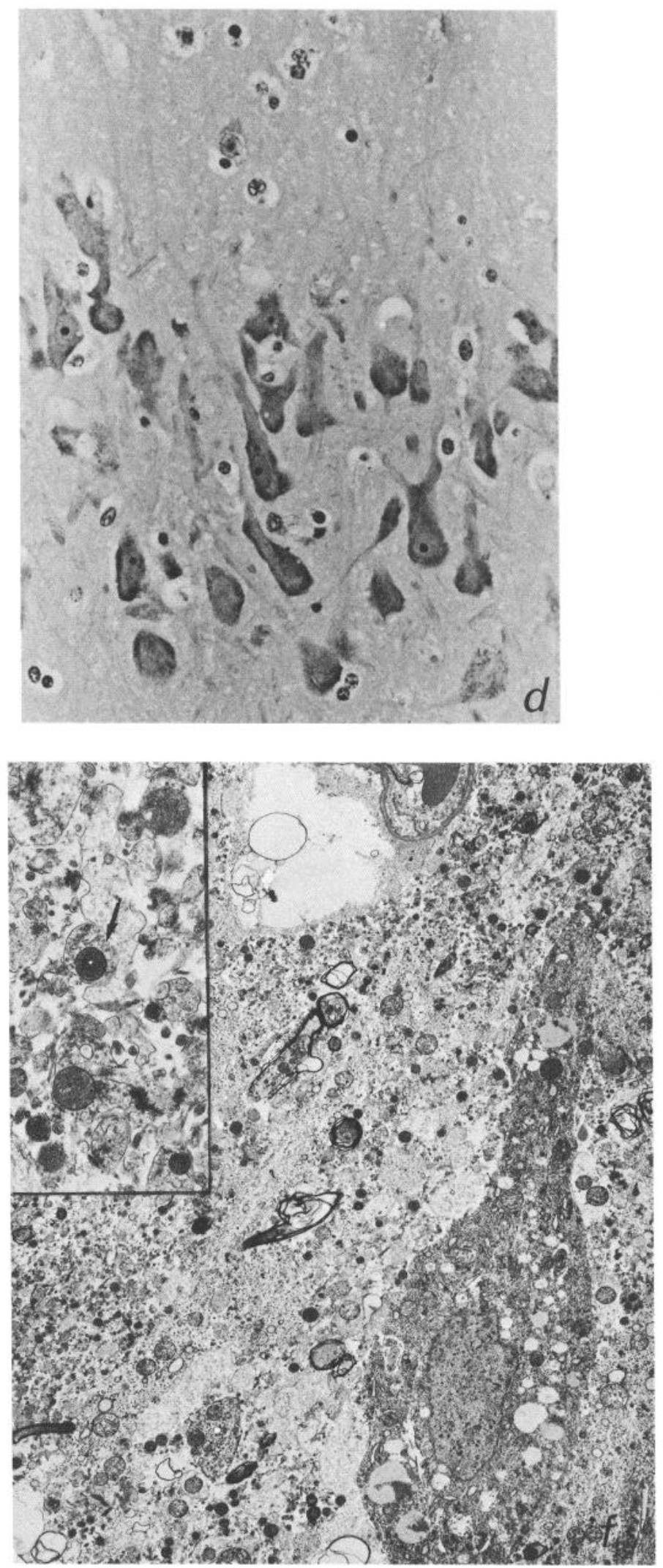

Adrenal tissue was prepared for light microscopy in the same way as was the neural tissue; after embedding, $2 \mu \mathrm{m}$ sections were cut and tissue stained in methylene blue and basic fuscin.

Statistical comparisons. Comparison of adrenal cortical measures be- 
Table 1. Experimental history and pathologic findings of study animals

\begin{tabular}{|c|c|c|c|c|c|c|c|c|c|}
\hline Subject & $\begin{array}{l}\text { Time in } \\
\text { captivity }\end{array}$ & Housing & $\begin{array}{l}\text { Experimental } \\
\text { history }\end{array}$ & $\begin{array}{l}\text { Weight } \\
(\mathrm{kg})\end{array}$ & $\begin{array}{l}\text { Clinical } \\
\text { history }\end{array}$ & Pathology & $\begin{array}{l}\text { P-M } \\
\text { time } \\
\text { (hr) }\end{array}$ & Scars & $\mathrm{NP}$ \\
\hline \multicolumn{10}{|l|}{ Controls } \\
\hline $212 \mathrm{M}$ & $4 \mathrm{yr}$ & Isolate & Repro & 4.3 & Euthanized & None & 0 & No & - \\
\hline$! 66 \mathrm{M}$ & $4 \mathrm{yr}$ & Isolate & Repro & 4.7 & Euthanized & None & 0 & No & - \\
\hline $225 \mathrm{M}$ & $9 \mathrm{yr}$ & Isolate & Schisto & 5.1 & Euthanized & Sch & 0 & No & - \\
\hline $907 \mathrm{~F}$ & $1 \mathrm{~d}$ & Isolate & Survey & 3.0 & Euthanized & None & 0 & No & - \\
\hline $340 \mathrm{~F}$ & $2 \mathrm{yr}$ & Social & Breeder & 2.4 & Euthanized & E-c & 0 & No & - \\
\hline $353 \mathrm{~F}$ & $2 \mathrm{yr}$ & Isolate & Repro & 3.2 & Postsurgery & Gut necr & 6 & No & - \\
\hline \multicolumn{10}{|c|}{ Ulcerated } \\
\hline $713 \mathrm{M}$ & $1 \mathrm{mo}$ & Social & Quar & 2.9 & SD & MGU & 12 & Yes & $* * *$ \\
\hline $522 \mathrm{M}$ & $6 \mathrm{mo}$ & Social & Breeder & 3.5 & $\mathrm{SD}$, coma & MGU, gu, e-c & 0 & No & $* * *$ \\
\hline $425 \mathrm{M}$ & $3 \mathrm{yr}$ & Isolate & Schisto & 2.5 & $\mathrm{SD}, \mathrm{d}, \mathrm{e}$ & MGU, sch, sld & 12 & No & $* *$ \\
\hline $873 \mathrm{~F}$ & $1 \mathrm{mo}$ & Social & Quar & 2.0 & $\mathrm{SD}$ & MGU & 12 & Yes & $* *$ \\
\hline $315 \mathrm{~F}$ & $2 \mathrm{yr}$ & Social & Breeder & 3.4 & $\mathrm{SD}, \mathrm{c}, \mathrm{nd}$ & MGU & 6 & Yes & $* *$ \\
\hline $278 \mathrm{~F}$ & $3 \mathrm{yr}$ & Isolate & Repro & 2.6 & $\mathrm{SD}$ & MGU, c & 0 & No & $* *$ \\
\hline $150 \mathrm{~F}$ & $4 \mathrm{yr}$ & Social & Breeder & 2.8 & $\mathrm{SD}$ & MGU, $\mathrm{g}, \mathrm{n}$ & 0 & Yes & $*$ \\
\hline $17 \mathrm{~F}$ & $11 \mathrm{yr}$ & Social & Breeder & 2.6 & $\mathrm{SD}, \mathrm{d}$, dhy & MGU, sld, acd & 12 & No & $*$ \\
\hline
\end{tabular}

Subjects: " $M$ " indicates male, " $F$ " indicates female.

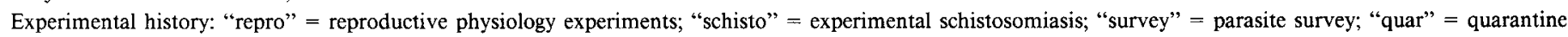
following trapping.

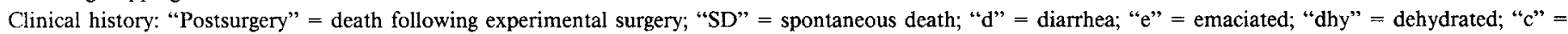
cough, "nd" = nasal discharge.

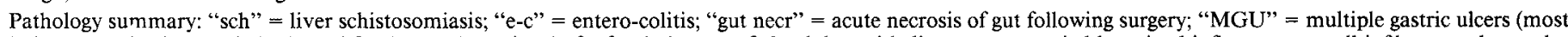

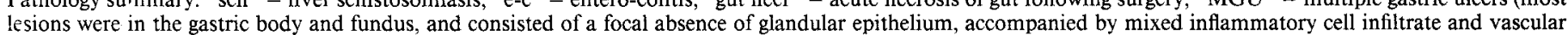
congestion); "gu" = gingival ulcer; "sld" = splenic lymphoid depletion; "acd" = adrenocortical degeneration; "c" = colitis; "g" = gingiva; " $\mathrm{n} "=$ neuropathy.

$\mathrm{P}-\mathrm{M}$ time indicates post-mortem time.

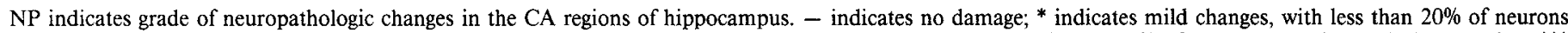

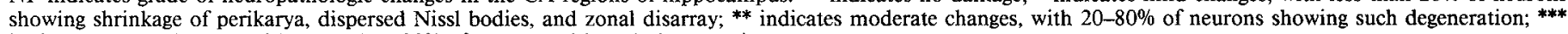
indicates severe changes, with more than $80 \%$ of neurons with such degeneration.

tween groups was made by unpaired $t$ tests. Comparison of neuron counts between groups in different hippocampal regions was made with 2-way ANOVA followed by Newman-Keuls post hoc tests.

\section{Results}

Compared with control tissue, pronounced neuronal degeneration was observed in the hippocampi of ulcerated animals. The circumferential extent of the CA3 region was generally reduced, and the pyramidal neurons throughout the CA regions were shrunken and sparse (Fig. 1, $a, b$ ). At higher magnification (Fig. $1, c, d)$, CA3 pyramidal neurons had reduced and irregularly shaped perikarya associated with dispersed Nissl bodies and atrophic dendritic branches. The stratum lucidum lost its clear interlaced texture made of the dendritic branches of CA3 pyramidal neurons and of the mossy fiber endings of the dentate granular neurons. Numerous swollen oligodendrocytes were observed (as round clear cells with pyknotic nuclei).

Hippocampal CA3 pyramidal neurons were then examined ultrastructurally (Fig. 1,e,f). Among ulcerated animals, Nissl bodies were dispersed and vesicle number increased. In more severe cases, in addition, perikaryon size was decreased and dendritic processes were narrowed. The mossy fiber terminals were depleted in the stratum lucidum, and preterminal fibers were dispersed. Moreover, synaptic vesicle number was reduced, and dendritic branches were edematous, with few neurotubules. Swollen oligodendrocytes had edematous cytoplasma containing dispersed ribosomes, many irregularly shaped vesicles, myelin sheaths, and lysosome-like dense bodies.

Similar changes occurred in CA1 and CA4 pyramidal neurons, but not in granular neurons of the dentate gyrus. Swollen oligodendrocytes were noted in the cerebral cortex, thalamus, hypothalamus, caudate, and pontine nuclei. No neuronal abnormalities were noted in these regions, except in the cerebral cortex, where varying degrees of shrinkage of pyramidal neurons occurred in layers 3-5 of the frontal, pre-, postcentral, and cingulate gyri (Fig. 2a).

Ultrastructural examination of the cerebral cortices of ulcerated monkeys showed pyramidal neurons with condensed perikaryonic cytoplasma, densely distributed ribosomes, many mitochondria, and irregularly shaped vesicles. Swollen oligodendrocytes were usually attached to shrunken neurons (satellitosis) (Fig. 2b).

The hippocampal degeneration among ulcerated male monkeys was also apparent quantitatively, with fewer pyramidal neurons in Ammon's horn cell regions than in control monkeys (Fig. 3).

The adrenal cortices of ulcerated animals showed substantial hyperplasia in the zona fasciculata and lesser amounts of hyperplasia in the other 2 cortical zones; hypertrophy of individual cortical cells was also noted (Fig. $4, a, b$ ). The average thickness of cortex was increased in ulcerated animals: $0.7 \pm 0.03$ versus $1.2 \pm 0.05$ for control and ulcerated, respectively $(p<0.01$, unpaired $t$ test). 

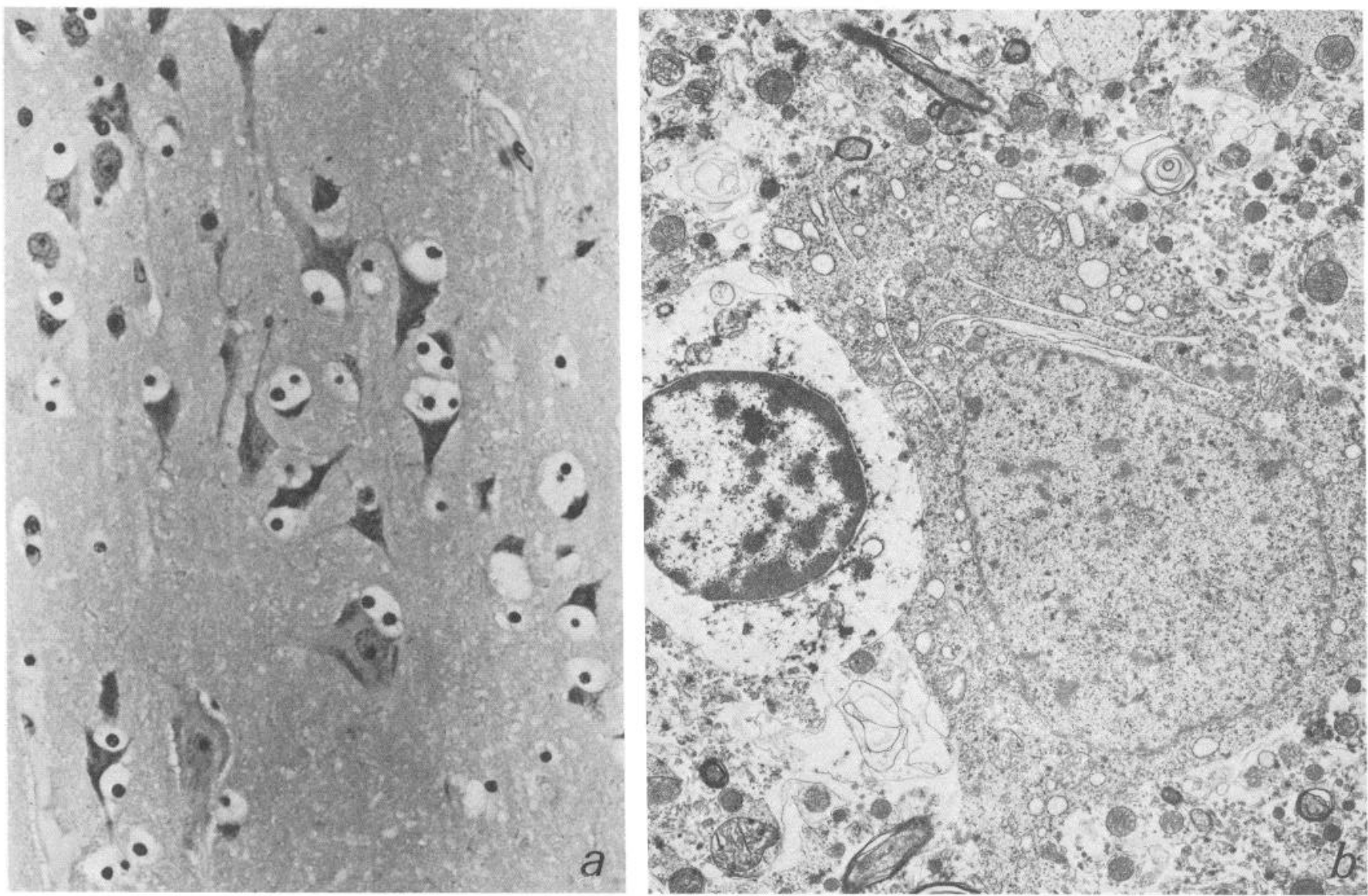

Figure 2. a, Shrinkage of pyramidal neurons with hydropic swelling and accumulation of satellite cells in postcentral gyrus in ulcerated animals. $\times 500$. $b$, Ultrastructure of a cortical pyramidal neuron and satellite cell showing condensation of neuron perikaryon and hydropic swelling of satellite cell. $\times 4000$.

\section{Discussion}

We have observed marked differences in the neuropathological profiles of ulcerated monkeys compared with healthy controls. The neuropathology in ulcerated monkeys was unlikely to have been an artifact of post-mortem decay since control animal $353 \mathrm{~F}$ had a post-mortem delay at least equal to half the ulcerated animals, yet had no degeneration, while all ulcerated animals necropsied immediately had damage. Moreover, the neuropathology was unlikely to have resulted from the agonal state of spontaneous death (versus euthanization) since control animal $353 \mathrm{~F}$ was not euthanized, yet had no degeneration. An exception to this is likely to have been the swollen oligodendrocytes observed throughout the brains of the ulcerated animals. This is generally considered to be a nonspecific artifact of either agonal state or post-mortem autolysis (Penfield and Cone, 1926; Brierley and Graham, 1984).

A number of observations suggest that the ulcerated animals were socially subordinate and under prolonged stress. Among captive groups of vervet monkeys, social behavior often involves persistent and escalating aggression culminating in serious injury, as well as an absence of ritualized gestures of social submission that serve to terminate aggression in other primate species; it is a typical aspect of social behavior that, under those conditions, it is subordinate animals that are subject to the highest rate of these social stressors (Rowell, 1971; Wolfheim and Rowell, 1972; Else, 1985; Kaplan, 1988). Six of 8 ulcerated monkeys came from social groups, whereas only 1 of 6 control animals did. Ulcerated animals from social groups appeared to have suffered higher rates of social harassment and attack than did control animals: 4 of 6 had bite scars at necropsy. In contrast, 5 other animals from social groups were examined as controls during that period, and none had bite wounds. Moreover, while GC concentrations could not be determined post-mortem, ulcerated animals had hyperplastic zona fasciculata of their adrenal cortices. As noted, this is the zone in which GCs are synthesized, and its hyperplasia is indicative of sustained GC hypersecretion (Bondy, 1985). In support of this view of ulcerated animals as chronically stressed, psychologic or social stress can be highly ulcerogenic in primates (Brady et al., 1958).

The anatomical and cellular patterns of damage in the ulcerated animals are in accord with what is known about GC-induced neurotoxicity. In the rat, it is the hippocampus that is preferentially damaged by elevated GC concentrations (see Sapolsky et al., 1986); moreover, it is the hippocampus in which normative, age-related neuron loss is halted by adrenalectomy or behavioral diminution of GC secretion (Landfield et al., 1981; Meaney et al., 1988). This hippocampal vulnerability is thought to arise from the extremely high concentrations of corticosteroid receptors in the structure (Sapolsky et al., 1986). The primate hippocampus is also a major GC-target tissue (McEwen et al., 1986), and ulcerated monkeys had preferential (although not 
Figure 3. Numbers of pyramidal neuhorn. Data for each animal were derived by averaging cell counts from 5 successive sections taken beginning 2 mm caudal to the uncus. ${ }^{*}, * *$ indicate $p<0.05,0.002$ compared with samesex controls (Newman-Keuls test following 2-way ANOVA). rons/coronal section through Ammon's

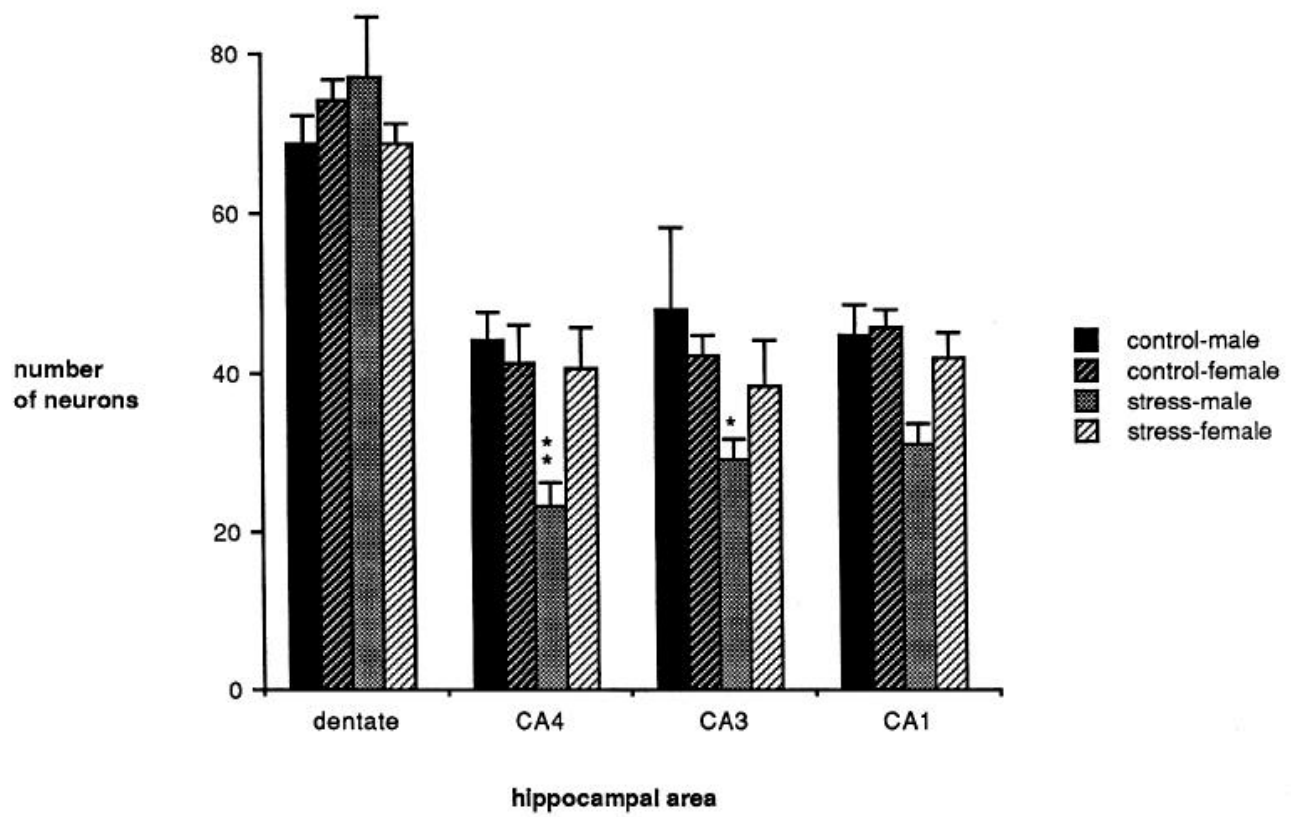

exclusive) hippocampal damage. Anatomical patterns of vulnerability within the hippocampus also suggest a causative role for GCs. In the rat, neuron loss during aging is minimal in the dentate gyrus and most pronounced in Ammon's horn pyramidal neurons (reviewed by Coleman and Flood, 1987). Furthermore, the dentate seems resistant to damage induced by prolonged GC exposure, while Ammon's horn neurons are particularly sensitive (Sapolsky et al., 1985). In the present case, a similar pattern of vulnerability occurred (Fig. 2). [It should be noted that the pattern of hippocampal damage induced, not by prolonged exposure to GCs alone, but by shorter exposures to GCs in synergy with various insults varies according to which insult is used (Sapolsky, 1986b).] Finally, prenatal exposure to GCs in the primate can damage the hippocampus. In that study,

Figure 4. Cross sections of adrenal gland from control $(a)$ and ulcerated $(b)$ monkeys. Arrows indicate corticomedullary boundary. $\times 10$.
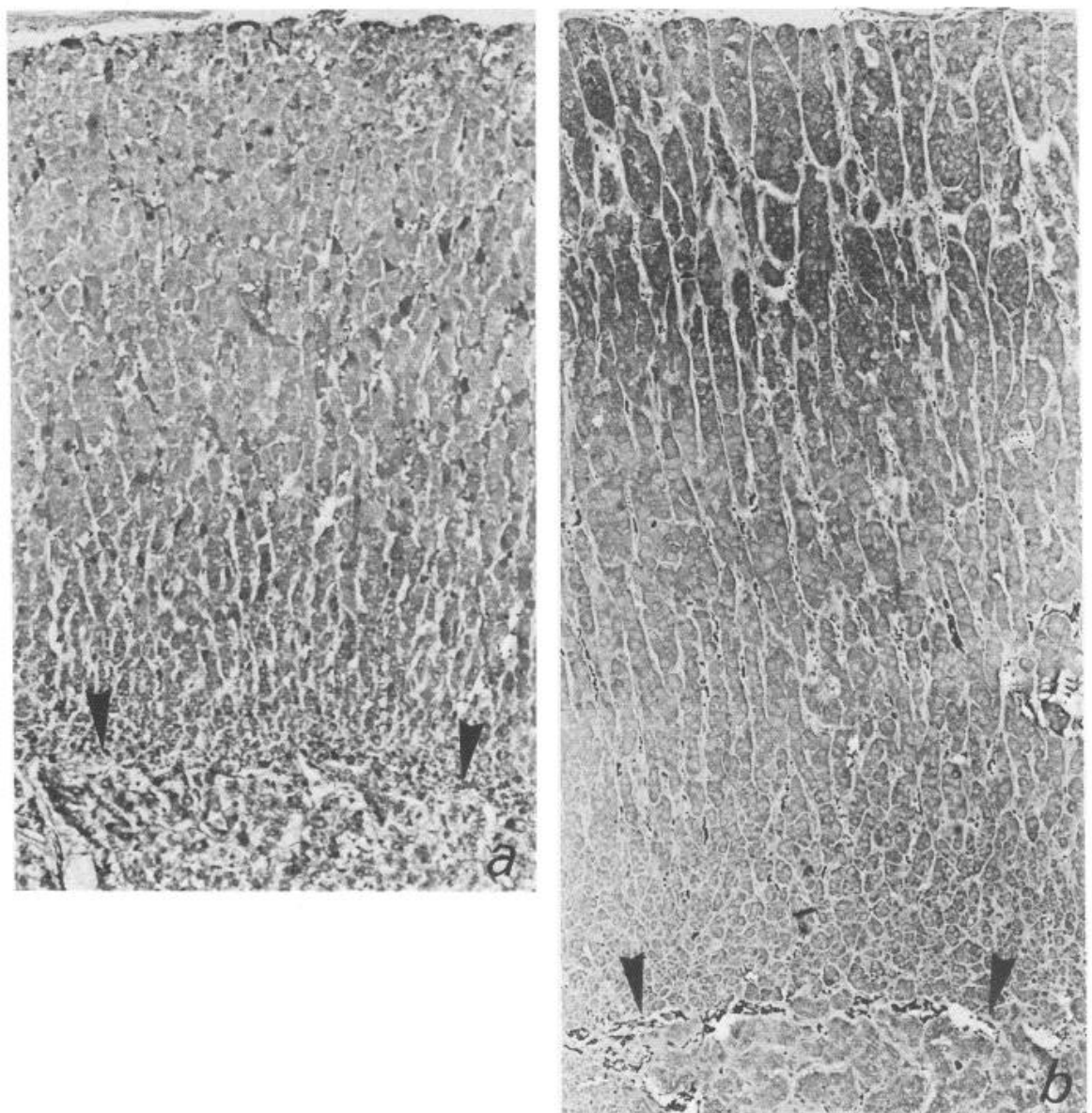
$133 \mathrm{~d}$ fetal rhesus monkeys were exposed to very high $(5 \mathrm{mg} /$ $\mathrm{kg}$ mother's body weight) concentrations of the synthetic GC, dexamethasone; near term, pyramidal neuron number was decreased; dendritic branches and axon terminals were swollen; vesicles, mitochondria, and neurotubules were dispersed in edematous axoplasm; and perikarya were atrophic (Uno et al., 1983).

Considerable variability in the severity of hippocampal damage occurred among ulcerated animals. This seemed not to be a function of the severity of peripheral pathologies at necropsy. Instead, more severe damage was observed among males (Fig. 2; Table 1), and among animals that had been captive a shorter time (Table 1). Unfortunately, these 2 trends covaried, and with the small sample size, it was not possible to determine whether one factor was more important. Were the sex difference to be the meaningful variable, it could reflect that ulcerated males were exposed to more severe stressors than were ulcerated females and/or were more vulnerable to the neurodegenerative effects of such stressors. In support of the former possibility, male vervets are often socially subordinate to females and are subject to high rates of attacks by them (Bernstein, 1970; Lancaster, 1971; Bramblett et al., 1982); to our knowledge, patterns of ulceration in wild vervets have never been studied.

In conclusion, a body of studies suggest that prolonged stress, via GC hypersecretion, can damage the rodent hippocampus, and the present data suggest, tentatively, a similar pattern in the primate. It may be beyond ethical bounds to attempt to demonstrate this more directly in a primate with an intentional experimental stressor. Nevertheless, the findings in this opportunistic study are suggestive: Ulcerated animals showed pathological and morphological indices of prolonged stress; anatomical and cellular features of damage among such animals were quite similar to those of rodent models of GC neurotoxicity; the precedent exists for (pharmacologic concentrations of) GCs damaging the fetal primate hippocampus. The potential implications of these observations are considerable, as the consequences of hippocampal damage for learning and memory are profound (Squire, 1986). The present data suggest that in the primate, hippocampal degeneration might constitute a "stressrelated" pathology, as well as a potential consequence of prolonged exogenous GC administration.

Note added in proof: We have since expanded this study to include more than a dozen such ulcerated animals and continue to see the same pattern of neuropathology. Previous investigators have noted a high incidence of multiple gastric ulcers among captive vervet monkeys and in one such case where behavioral data had becn collected on individuals, these were found to be socially subordinate animals (F. Ervin, personal communication).

\section{References}

Aus der Muhlen, K., and H. Ockenfels (1969) Morphologische Veranderungen im Deincephalon und Telencephalon nach Storngen des regelkreises Adenohypophyse-Nebennierenrinde III. Ergebnisse beim Meerschweinchen nach Verabreichung von Cortison und Hydrocortison. Z. Zellforsch. 93: 126-138.

Bernstein, I. (1970) Primate status hierarchies. In Primate Behavior, Vol. 1, L. Rosenblum, ed., pp. 71-109, Liss, New York.

Bondy, P. (1985) Disorders of the adrenal cortex. In Textbook of Endocrinology, Vol. 7, J. Wilson and D. Foster, eds., pp. 816-890, Saundcrs, Philadclphia.

Brady, J., R. Porter, D. Conrad, and J. Mason (1958) Avoidance behavior and the development of gastroduodenal ulcers. J. Exp. Anal. Behav. 1: 69-72.
Bramblett, C., S. Bramblett, D. Bishop, and A. Coelho (1982) Longitudinal stability in adult status hierarchies among vervet monkeys (Cercopithecus aethiops). Am. J. Primatol. 2: 43-51.

Bricrlcy, J., and D. Graham (1984) Hypoxia and vascular disorders of the central nervous system. In Greenfield's Neuropathology, 4th ed., J. Adams, J. Corsellis, and L. Duchen, eds., pp. 125-207, Wiley, New York.

Coleman, P., and D. Flood (1987) Neuron numbers and dendritic extent in normal aging and Alzheimer's disease. Neurobiol. Aging 8: $521-546$

Else, J. (1985) Captive propagation of vervet monkeys (Cercopithecus aethiops) in harems. Lab. Anim. Med. 35: 373-375.

Kadekaro, M., M. Ito, and P. Gross (1988) Local cerebral glucose utilization is increased in acutely adrenalectomized rats. Neuroendocrinology 47: 329-334.

Kaplan, J. (1988) Dominance and affiliation in the Cercopithecini and Papionini; a comparative examination. In Comparative Behavior of African Monkeys, E. Zucker, ed., Liss, New York (in press).

Koide, T., T. Wieloch, and B. Siesjo (1986) Chronic dexamethasone pretreatment aggravates ischemic neuronal necrosis. J. Cerebr. Blood Flow Metab. 6: 395-403.

Krieger, D. (1982) Cushing's Syndrome. In Monographs Endo. Vol. 22, Springer-Verlag, Berlin.

Lancaster, J. (1971) Play-mothering: The relations between juvenile females and young infants among free-ranging vervet monkeys $(\mathrm{Cer}$ copithecus aethiops). Folia Primatol. 15: 161-182.

Landfield, P., R. Baskin, and T. Pitler (1981) Brain aging correlates: Retardation by hormonal-pharmacological treatments. Science 214: 581-584.

McEwen, B., E. de Kloet, and W. Rostene (1986) Adrenal steroid receptors and actions in the nervous system. Phys. Rev. 66: 11211189.

Meaney, M., D. Aitken, S. Bhatnager, C. van Berkel, and R. Sapolsky (1988) Effect of neonatal handling on age-related impairments associated with the hippocampus. Science 239: 766-769.

Munck, A., P. Guyre, and N. Holbrook (1984) Physiological functions of glucocorticoids during stress and their relation to pharmacological actions. Endocr. Rev. 5: 25-48.

Penfield, W., and W. Cone (1926) Acute swelling of ligodendroglia. A specific type of neuroglia change. Arch. Neurol. Psychiatry 16:131153.

Rowell, T. (1971) Organization of caged groups of Cercopithecus monkeys. Anim. Behav. 19:625-645.

Sapolsky, R. (1985a) A possible mechanism for glucocorticoid toxicity in the hippocampus: Increased vulnerability of neurons to metabolic insults. J. Neurosci. 5: 1228-1232.

Sapolsky, R. (1985b) Glucocorticoid toxicity in the hippocampus: Temporal aspects of neuronal vulnerability. Brain Res. 339: 300-306.

Sapolsky, R. (1986a) Glucocorticoid toxicity in the hippocampus: Synergy with an excitotoxin. Neuroendocrinology 43: 440-446.

Sapolsky, R. (1986b) Glucocorticoid toxicity in the hippocampus: Reversal by supplementation with brain fuels. J. Neurosci. 6: 22402247.

Sapolsky, R., and W. Pulsinelli (1985) Glucocorticoids potentiate ischemic injury to neurons: Therapeutic implications. Science 229: $1397-$ 1400.

Sapolsky, R., L. Krey, and B. McEwen (1985) Prolonged glucocorticoid exposure reduces hippocampal neuron number: Implications for aging. J. Neurosci. 5: 1221-1227.

Sapolsky, R., L. Krey, and B. McEwen (1986) The neuroendocrinology of stress and aging: The glucocorticoid cascade hypothesis. Endocr. Rev. 7: 284-303.

Sapolsky, R., D. Packan, and W. Vale (1988) Glucocorticoid toxicity in the hippocampus: In vitro demonstration. Brain Res. 453: 367371.

Squire, L. (1986) Mechanisms of memory. Science 232: 1612-1619.

Suleman, M., R. Tarara, and P. Sayer (1984) Gastric ulcers in vervet monkeys (Cercopithecus aethiops). Int. J. Primatol. 5: (abstr. 0215).

Theoret, Y., J. Caldwell-Kenkel, and M. Krigman (1985) The role of neuronal metabolic insult in organometal neurotoxicity. Toxicologist 6: 491 (abstr.).

Uno, H., C. Thieme, J. Kemnitz, and P. Farrell (1983) Effect of dexamethasone on the cerebral cortical development of the rhesus monkey. Soc. Neurosci. Abstr. 320: 3.

Wolfheim, J., and T. Rowell (1972) Communication among captive talapoin monkeys (Miopthecus talapoin). Folia Primatol. 18: 224 255. 